\title{
Recent Development of VUV-Based Processes for Air Pollutant Degradation
}

\author{
Haibao Huang ${ }^{1,2 *}$, Haoxian Lu $^{1}$, Huiling Huang ${ }^{1}$, Lei Wang ${ }^{1}$, Jieni Zhang ${ }^{1}$ and \\ Dennis Y. C. Leung ${ }^{3 *}$ \\ ${ }^{1}$ Department of Environmental Engineering, School of Environmental Science and Engineering, Sun Yat-Sen University, \\ Guangzhou, China, ${ }^{2}$ Guangdong Provincial Key Laboratory of Environmental Pollution Control and Remediation Technology, \\ Sun Yat-sen University, Guangzhou, China, ${ }^{3}$ Department of Mechanical Engineering, The University of Hong Kong, \\ Hong Kong, Hong Kong
}

OPEN ACCESS

Edited by:

Rajasekhar Balasubramanian, National University of Singapore, Singapore

Reviewed by:

Eduardo Landulfo, Instituto de Pesquisas Energéticas e Nucleares, Brazil Cláudia Gomes Silva, Associate Laboratory LSRE-LCM, Portugal

*Correspondence: Haibao Huang seabao8@gmail.com

Dennis Y. C. Leung ycleung@hku.hk

Specialty section:

This article was submitted to Air Pollution

a section of the journa

Frontiers in Environmental Science

Received: 09 January 2016

Accepted: 29 February 2016

Published: 15 March 2016

Citation:

Huang $H$, Lu H, Huang $H$, Wang $L$,

Zhang $J$ and Leung DYC (2016)

Recent Development of VUV-Based

Processes for Air Pollutant

Degradation. Front. Environ. Sci. 4:17.

doi: 10.3389/fenvs.2016.00017
As air pollution poses a great challenge around the globe, it is essential to fashion out a way of efficiently degrading the air pollutants. Vacuum Ultraviolet (VUV)-based processes are an emerging and promising technology for environmental remediation such as air cleaning, wastewater treatment, and air/water disinfection. When VUV irradiation, photolysis, photocatalysis, and ozone-assisted oxidation are involved at the same time, it results in the fast degradation of air pollutants because of their strong oxidizing capacity. The mechanisms of how the oxidants are produced and how they react are discussed in this review. This paper focuses mainly on the three VUV-based oxidation processes including VUV photolysis, VUV combined with ozone-assisted oxidation, and VUV-PCO with emphasis on their mechanisms and applications. Also, the outlook of these processes are proposed in this paper.

Keywords: VUV-PCO, photolysis, ozone-assisted oxidation, photocatalysis, air pollutants

\section{INTRODUCTION}

\section{Common Air Pollutions}

With the rapid development of industry and increasing population, air pollutions presently poses a more serious challenge. Solving the problem of air pollution is one of the most difficult challenges faced by a number of governments around the world (Spigno et al., 2003). Air pollutants, including biological and gaseous substances exist in ambient as well as in indoor environments and require simultaneous removal for better air quality (Yu et al., 2009). Gaseous pollutants can be classified into organic and inorganic, and among them organic compounds take a majority of the emission category. Inorganic pollutants mainly refer to sulfur dioxide, nitric oxide, hydrogen sulfide, and so on, while organic pollutants mainly consist of Volatile Organic Compounds (VOCs) with boiling points between room temperature and $260^{\circ} \mathrm{C}$ (Huang et al., 2015b) including alkanes, aromatic hydrocarbons, aromatics, olefins, alcohols, aldehydes, ketones, halogenated hydrocarbon, and so on. Among the list of 25 toxic gaseous pollutants listed by U.S. EPA, 18 of them are organic compounds (Lee, 1991). The generation, transportation and storage processes of the raw chemicals and industries, such as pharmaceutical chemicals, printing, and petrochemical industries produce most of the VOCs (Li et al., 2009; Brito et al., 2015). VOCs cause great harm to the human health. Long time exposure to VOCs may cause health problems, such as Sick Building Syndromes (SBS) (Järnström et al., 2006), cancer, genetic mutation, and so on. It can also cause air pollution like PM2.5, photochemical smog, ozone, and global warming (McGwin et al., 2010; Wu et al., 2012). 
In the past, most of the studies focused on the degradation of single pollutant but not on multiple air pollutants (Thiruvenkatachari et al., 2008). VUV-based processes are advanced oxidation processes (AOPs) without selectivity, which is of a great advantage for the degradation of multiple air pollutants.

\section{Common Air Purification Methods}

Air purification process can be generally divided into physical, chemical, and biological methods.

\section{Physical Methods}

In physical methods, pollutants can be separated from waste gas due to the different physical properties like boiling point and solubility. It can be divided into absorption, adsorption, membrane separation, and condensation. Moretti et al. (Moretti, 2002) tried to absorb the organic gas by Nonpolar mineral oil such as light diesel and engine oil with a removal efficiency of 90\%. Noll (Standeker et al., 2009), Moura (Moura et al., 2011), Daifullah (Daifullah and Girgis, 2003), and Kwong (Kwong and Chao, 2010) adopted the silica aerosol, alumina, activated carbon, and fly-ash in order to adsorb VOCs. High removal rate of VOCs can be achieved under membrane separation (Xing et al., 2000). Baker et al. (1994) recycled VOCS from waste gas by compression, condensation, and membrane separation.

However, there are some disadvantages that tend to limit the application of physical methods. For example, most of the VOCs are insoluble in water which reduces the absorption efficiency. In addition, the solution after absorption needs further disposal. Although the adsorption process is simple and it can also recycle the useful compounds of the waste gas, secondary pollution will occur during the desorption process which may increase the cost. The high cost also greatly restricts the application of membrane separation.

\section{Biological Methods}

In biological treatment, pollutants are generally decomposed into carbon dioxide, water, and cytoplasm by microbial metabolism (Deshusses and Johnson, 2000). Biological degradation has many operational and cost advantages over the conventional physicochemical methods (Aizpuru et al., 2001). Niu et al. (2014) discovered that a bio-tricking filter can be used to remove inorganic pollutants such as NO from air stream using bacteria extracted from waste water sludge. Lu et al. (2000) used biotrickling to destruct BTEX vapor and they found that more than 90\% BTEX could be achieved. Rene et al. (2009) discovered that removal efficiencies of benzene is higher than $90 \%$ in a laboratory scale bio-filtration. However, this system needs a large area and long start-up time (Wang et al., 2008).

\section{Chemical Methods}

Chemical methods can remove pollutants by a series of reactions like neutralization and redox reactions. The processes include incineration and catalytic combustion (Barbero et al., 2008), plasma treatment (Daniels, 2002), and acid-base spray (Dulin and Rosar, 1975). Harmful substances can be degraded completely into non-toxic substances by chemical methods. However, the cost is higher than physical and biological methods as special chemicals are needed in the processes, thus, it is highly necessary to reduce their cost. The required temperature of VOCs catalytic combustion can be greatly decreased by developing efficient catalysts, thereby reducing the energy consumption. Wang et al. (Wang, 2004) adopted $\gamma-\mathrm{Al}_{2} \mathrm{O}_{3}$ supported transition-metal oxide catalysts in order to oxidize methylbenzene which can be degraded completely under a temperature of $360^{\circ} \mathrm{C}$. Wang et al. (2006) also used $\mathrm{CuO} / \mathrm{CeO}_{2}$ for catalytic oxidation of toluene which can be completely degraded at temperature lower than $240^{\circ} \mathrm{C}$.

As shown above, the application of traditional technology is limited by some disadvantages such as byproducts, cost, and degradation capacity. Therefore, it is essential to develop a costeffective and environmental-friendly treatment method under increasingly complicated air pollution problems and stringent air quality standards. As such AOPs have been studied for air pollution control because of its high efficiency and mild reaction condition (Zhu et al., 2015). Among them, VUV-based processes are emerging processes for the degradation of air pollutants that can provide an efficient solution for air pollution control.

\section{Introduction of UV and VUV Irradiation}

UV irradiation refers to the electromagnetic radiation with wavelength from 1 to $380 \mathrm{~nm}$. It can be categorized into UVA (380-315 nm), UV-B (315-280 nm), UV-C (280-200 nm), vacuum-UV (VUV, 200-100 nm), and extreme UV (100-1 nm) (Oppenländer, 2003). The main method used to produce UV radiation is through the discharge from low pressure mercury lamp. Medium pressure mercury lamp can also be used to produce UV-A, UV-B, and UV-C. However, UV$B$ and UV-C can be absorbed by the glass tube and it needs special material like quartz to avoid loss of UV light (Thiruvenkatachari et al., 2008). As for the VUV lamp, it required a quartz with high purity in order to prevent the absorption of the shorter wavelength's UV irradiation. Therefore, barrier discharge (Masschelein and Rice, 2002) and Xe-excimer radiators (Wang et al., 2010) are generally used to produce VUV irradiation.

Recently, among the different AOPs, VUV-based processes have attracted much attention in the degradation of air pollutants. Yang (Yang et al., 2007), Huang (Huang et al., 2011), and Jiang (Jiang et al., 2015) have tried to eliminate the air pollutants with VUV photolysis. Compared with UV, VUV can degrade air pollutants more efficiently due to the following reasons: (1) VUV can directly destruct the compounds due to its energetic photons; (2) With certain humidity, VUV irradiation can interact with water vapor and produce hydroxyl radicals that can degrade compounds; (3) Oxygen species like $\mathrm{O}\left({ }^{1} \mathrm{D}\right)$, $\mathrm{O}\left({ }^{3} \mathrm{P}\right)$, and $\mathrm{O}_{3}$ can be formed from the reaction between VUV irradiation and oxygen (Bergonzo and Boyd, 1993; Hashem et al., 1997; Fu et al., 2011). When degradation capacity and cost are put into consideration, the application of VUV becomes more attractive. However, it also has some disadvantages such as the formation of residual ozone that will cause secondary pollution. 


\section{GENERATION OF THE OXIDANTS}

General VUV-based processes include the VUV photolysis (Alapi and Dombi, 2007a), VUV-PCO (Huang et al., 2011), VUV combined with Ozone-assisted Catalytic Oxidation (VUV-OZCO) (Huang, 2015). The sections below will focus on the oxidants generated from these three processes.

\section{Hydroxyl Radicals Formation Photolysis}

As the wavelength of VUV spectral domain (100-200 nm, mainly at $185 \mathrm{~nm}$ ) is shorter than that of normal UV (Gonzalez et al., 2004), it can produce photons with higher energy level. Therefore, many studies have been carried out to achieve photo-degradation of pollutants by VUV photolysis alone (Ye et al., 2014). Energetic photons play an important role in the degradation process because they can result in direct degradation of the pollutants and in the formation of oxidizing species like hydroxyl radical and ozone that can oxidize pollutants (Bergonzo and Boyd, 1993; Kutschera et al., 2009; Zoschke et al., 2014). Hydroxyl radical is highly reactive for the oxidation of the pollutants in gaseous or aqueous phase with no selectivity.

In the VUV photolysis of aqueous reaction systems, photolysis of water is the main pathway to produce hydroxyl radical (Gonzalez et al., 2004; Zoschke et al., 2014). Water absorbs light strongly at wavelengths lower than $190 \mathrm{~nm}$. However, due to the high absorption rate, the VUV irradiation is absorbed within a narrow layer around the lamp (approx. $300 \mathrm{~mm}$ at $185 \mathrm{~nm}$ ) (Kutschera et al., 2009). The ionization of water occur via the homolysis (Equation 1) and photochemical (Equation 2; Zoschke et al., 2014) reactions. The oxidants formed are mainly hydroxyl radicals, hydrogen atoms, and solvated electrons all of which initiate manifolds of reduction and oxidation reactions (Oppenländer, 2003). The quantum yields $(\varphi)$ of the hydroxyl radical and the solvated electrons are 0.33 and 0.045 , respectively (Lopez et al., 2000; Kutschera et al., 2009).

$$
\begin{aligned}
& \mathrm{H}_{2} \mathrm{O} \stackrel{\mathrm{hv}(185 \mathrm{~nm})}{\longrightarrow} \cdot \mathrm{OH}+\cdot \mathrm{H} \quad \varphi=0.33 \\
& \mathrm{H}_{2} \mathrm{O} \stackrel{\mathrm{hv}(185 \mathrm{~nm})}{\longrightarrow} \cdot \mathrm{OH}+\mathrm{H}^{+}+\mathrm{e}_{\mathrm{aq}}^{-} \varphi=0.045
\end{aligned}
$$

In the same way, the photolysis of moisture gas takes place in gaseous phase and hydroxyl radicals are generated with the VUV irradiation. In addition, another way to form $\cdot \mathrm{OH}$ is in a humidified $\mathrm{O}_{2}$ stream which can open up another pathway for the decomposition of pollutants. With wavelengths under $220 \mathrm{~nm}$, oxygen can be dissociated into two $\mathrm{O}$ atoms (Equation 3; Atkinson et al., 1996). The $\mathrm{O}$ atom does not only interact with water to produce hydroxyl radicals (Equation 4), it also reacts with oxygen to produce ozone (Equation 5; Alapi and Dombi, 2007b). Therefore, there is a competition between the generation of hydroxyl radicals and ozone. It was reported that humidity inhibits $\mathrm{O}_{3}$ formation in an $\mathrm{O}_{2}$ stream and $\cdot \mathrm{OH}$ will be formed due to the reaction of $\mathrm{O}$ atom and water (Atkinson et al., 1996). Further reactions in the system will lead to the formation of hydrogen peroxide (Ye et al., 2013; Equations 7-9). Also, the generated $\mathrm{H}_{2} \mathrm{O}_{2}$ will also be decomposed into hydroxyl radicals (Equation 10) under the irradiation of 185 and $254 \mathrm{~nm}$ UV light (Atkinson et al., 2004).

$$
\begin{aligned}
& \mathrm{O}_{2} \stackrel{\mathrm{hv}}{\leq} \stackrel{220 \mathrm{~nm}}{\longrightarrow} 2 \mathrm{O}
\end{aligned}
$$

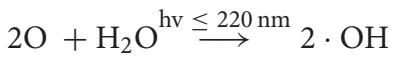

$$
\begin{aligned}
& \mathrm{O}+\mathrm{O}_{2}+\mathrm{M} \rightarrow \mathrm{O}_{3}+\mathrm{M} \\
& \cdot \mathrm{H}+\mathrm{O}_{2}+\mathrm{M} \rightarrow \cdot \mathrm{HO}_{2}+\mathrm{M} \\
& \cdot \mathrm{OH}+\cdot \mathrm{OH}+\mathrm{M} \rightarrow \mathrm{H}_{2} \mathrm{O}_{2}+\mathrm{M} \\
& \cdot \mathrm{HO}_{2}+\cdot \mathrm{HO}_{2} \rightarrow \mathrm{H}_{2} \mathrm{O}_{2}+\mathrm{O}_{2} \\
& \cdot \mathrm{H} \mathrm{O}_{2}+\cdot \mathrm{HO}_{2}+\mathrm{M} \rightarrow \mathrm{H}_{2} \mathrm{O}_{2}+\mathrm{O}_{2}+\mathrm{M} \\
& \mathrm{H}_{2} \mathrm{O}_{2} \stackrel{\text { hv(185 } \mathrm{nm} \text { and } 254 \mathrm{~nm})}{\longrightarrow} 2 \cdot \mathrm{OH}
\end{aligned}
$$

Overall, hydroxyl radicals are generated in gaseous phase via four pathways: (1) homolysis of water, (2) photochemical ionization of water, (3) reactions between $\mathrm{O}$ atom and water, and (4) photolysis of hydrogen peroxide.

\section{Photocatalysis of Semiconductor}

Hydroxyl radicals produced by photolysis are mainly attributed to the $185 \mathrm{~nm}$ UV irradiation. However, VUV lamp can only emit $<10 \% 185 \mathrm{~nm}$ irradiation while the majority $254 \mathrm{~nm}$ UV irradiation has not been fully utilized in photolysis (Alapi and Dombi, 2007a). Therefore, semiconductor like $\mathrm{TiO}_{2}$ was used to produce more hydroxyl radicals via photocatalysis. The mechanism of photocatalytic oxidation (PCO) is similar to that of $\mathrm{UV} / \mathrm{TiO}_{2}$, which is shown in Figure 1.

As one of the semiconductor catalysts, $\mathrm{TiO}_{2}$ photocatalytic material has special electronic structure. Unlike metals which have a continuum of electronic states, semiconductors possess a void energy region where low energy levels are available to promote recombination of electrons and holes produced by photo-activation within the material. The void region which extends from the top of the filled valence band to the bottom of the vacant conduction band is called the band gap (Linsebigler et al., 1995). With the irradiation of UV light, $\mathrm{TiO}_{2}$ absorbs the energy of photon. When the energy of photon is higher than the width of the semiconductor's void band, the electron of valence band will transfer to the conduction band. Therefore,

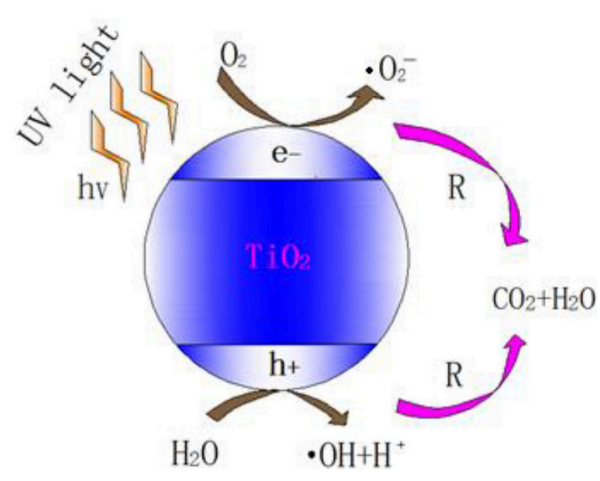

FIGURE 1 | Scheme of photocatalysis of TiO2 (Tompkins et al., 2005). 
the pairs of electron-holes are created in the semiconductor, and the charge will be transferred between electron-hole pairs and adsorbed species (reactants) on the semiconductor surface, photo-oxidation will then occur (Zhao and Yang, 2003).

The photo-generated electron $\left(\mathrm{e}^{-}\right)$has strong redox potential and is able to reduce the electron acceptor of the semiconductor's surface. The photo-generated hole $\left(\mathrm{h}^{+}\right)$generated by activation is a strong oxidant. It reacts with absorbed water $\left(\mathrm{H}_{2} \mathrm{O}\right)$ or surface hydroxyl ion chemically $\left(\mathrm{OH}^{-}\right)$and produces hydroxyl radical with strong oxidizing property (Schwitzgebel et al., 1995).

$\mathrm{O}_{2}$ and $\mathrm{H}_{2} \mathrm{O}$ will interact with the electrons and photogenerated holes in humid air. The overall reaction is as follows (Konstantinou and Albanis, 2004): First, $\mathrm{O}_{2}$ and $\mathrm{H}_{2} \mathrm{O}$ are absorbed on the surface of the $\mathrm{TiO}_{2}$ and then form adsorbed oxygen and adsorbed water, respectively (Equations $11,12)$. Subsequently, the surface of the $\mathrm{TiO}_{2}$ produces photogenerated electron $\left(\mathrm{e}^{-}\right)$and photo-generated hole $\left(\mathrm{h}^{+}\right)$under UV irradiation (Equation 13).

$$
\begin{array}{r}
\mathrm{O}_{2}(\mathrm{~g}) \mathrm{O}_{2} \rightarrow(\text { ads }) \\
\mathrm{H}_{2} \mathrm{O}(\mathrm{g}) \rightarrow \mathrm{H}_{2} \mathrm{O}(\text { ads }) \\
\mathrm{TiO}_{2} \stackrel{\mathrm{hv}}{\longrightarrow} \mathrm{TiO}_{2}\left(\mathrm{e}^{-}+\mathrm{h}^{+}\right)
\end{array}
$$

Afterwards, the photo-generated hole is captured by the surface of adsorbed water and hydroxyl ion, producing hydroxyl radicals (Equations 14, 15).

$$
\begin{array}{r}
\mathrm{h}^{+}+\mathrm{H}_{2} \mathrm{O} \rightarrow \cdot \mathrm{OH}+\mathrm{H}^{+} \\
\mathrm{h}^{+}+\mathrm{OH}^{-} \rightarrow \cdot \mathrm{OH}
\end{array}
$$

Furthermore, the addition of $\mathrm{O}_{2}$ leads to an increase in the upward band bending, and therefore, suppresses the electronhole recombination process, leading to a more efficient photoactivity (Linsebigler et al., 1995). Meanwhile, further reaction will continuously produce hydroxyl radical (Equations 16-19).

$$
\begin{array}{r}
\mathrm{e}^{-}+\mathrm{O}_{2}(\text { ads }) \rightarrow \cdot \mathrm{O}_{2}^{-} \text {(ads) } \\
\cdot \mathrm{O}_{2}^{-} \text {(ads) }+\mathrm{H}^{+} \rightarrow \cdot \mathrm{HO}_{2} \\
2 \cdot \mathrm{HO}_{2} \rightarrow \mathrm{O}_{2}+\mathrm{H}_{2} \mathrm{O}_{2} \\
\mathrm{H}_{2} \mathrm{O}_{2}+\cdot \mathrm{O}_{2}^{-} \text {(ads) } \rightarrow \cdot \mathrm{OH}+\mathrm{O}_{2}+\mathrm{OH}^{-}
\end{array}
$$

\section{Generation of Ozone}

The VUV irradiation at $185 \mathrm{~nm}$ can be used for the generation of ozone using oxygen. As shown in Equations (3) and (5), $\mathrm{O}$ atom will be generated by the photolysis of oxygen when absorbing VUV irradiation and then reacted with an oxygen molecule, forming ozone. This reaction takes place in the presence of a molecule $\mathrm{M}$ which absorbs the excessive kinetic energy (Bolton and Denkewicz, 2008). Meanwhile, ozone can be decomposed by $254 \mathrm{~nm}$ UV irradiation, forming an $\mathrm{O}$ atom and an oxygen molecule, as shown in Equation 20.

$$
\begin{aligned}
& \mathrm{O}_{2} \stackrel{\text { hv }}{\leq 220 \mathrm{~nm}} 2 \mathrm{O} \\
& \mathrm{O}+\mathrm{O}_{2}+\mathrm{M} \rightarrow \mathrm{O}_{3}+\mathrm{M}
\end{aligned}
$$

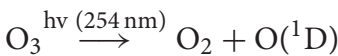

The yield of ozone from VUV irradiation is very low. About $9 \mathrm{~g} / \mathrm{kWh}$ and $7.2 \mathrm{~g} / \mathrm{kWh}$ of ozone can be produced from oxygen and air, respectively (Hashem et al., 1997). Two reasons might be responsible for the low ozone generation. First, the emission intensity at $185 \mathrm{~nm}$ constitutes only $8 \%$ of all UV irradiation. Also, partial ozone could be decomposed by $254 \mathrm{~nm}$ UV light. In addition, VUV irradiation can be easily absorbed by the water vapor. The generated $\mathrm{O}_{3}$ increases with the decreasing water content. Ye et al. (2013) studied the effect of the operating parameters on ozone formation. It was found that $\mathrm{H}_{2} \mathrm{O}$ and $\mathrm{O}_{2}$ contents, as well as flow rate, could significantly affect $\mathrm{O}_{3}$ production. The increased $\mathrm{H}_{2} \mathrm{O}$ content led to the decreased $\mathrm{O}_{3}$ production, whereas $\mathrm{O}_{2}$ content had an opposite effect.

Despite the low ozone yields of low-pressure mercury vapor lamps, ozone generation and photolysis of pollutants can be simultaneously achieved by a single irradiation source (Hashem et al., 1997). The VUV systems with internal ozone generation has been used for the disinfection of micro-pollutants (Bolton and Denkewicz, 2008; Zoschke et al., 2012), as shown in Figure 2. The air or oxygen go through the annular space between the UV lamp and the quartz sleeve which can absorb the VUV radiation at $185 \mathrm{~nm}$ to generate ozone. The gas containing ozone is injected into the water on the other side of the quartz sleeve. In addition, the UV/VUV radiation passes directly through the quartz sleeve into water to achieve the photolysis of an aqueous phase.

Ozone is a strong oxidant and has a great potential to be utilized for the degradation of pollutants. It was reported that high efficiency of degradation of benzene (Einaga and Futamura, 2004a; Einaga et al., 2009), ethanol (Shayan and Vahedpour, 2013), and acetone (Reed et al., 2006) can be achieved by ozone catalytic oxidation treatment.

The key of ozone catalytic oxidation technology is the preparation of catalysts with high $\mathrm{CO}_{2}$ selectivity, stability, and removal efficiency. Ozone decomposition catalysts consist

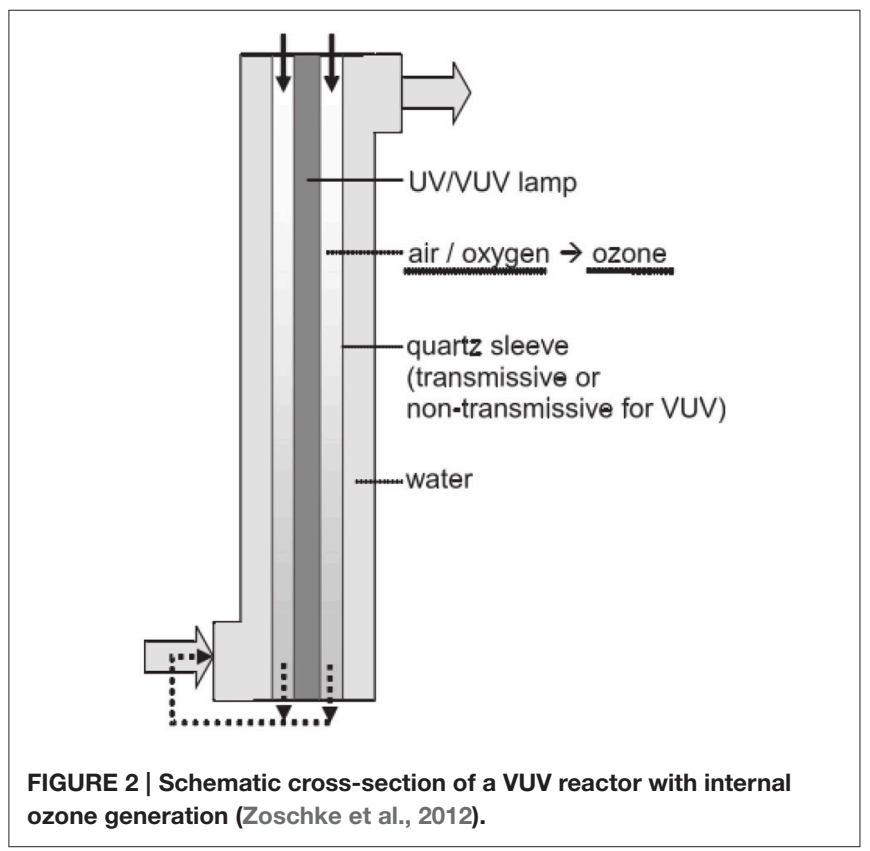


of precious metals (such as palladium, silver) and transition metal oxides, and so on. The application of precious metals is greatly limited by its high cost and the difficulty of regeneration. In recent years, transition metal oxides have attracted much attention. Among the transition metal oxides, the supported catalysts are more attractive because of its lower cost and better catalytic stability. The supports include $\mathrm{Al}_{2} \mathrm{O}_{3}$ (Einaga and Futamura, 2004b, 2005; Konova et al., 2006), $\mathrm{TiO}_{2}$ (Radhakrishnan and Oyama, 2001), $\mathrm{SiO}_{2}$, and molecular sieve (Einaga et al., 2013). Einaga (Einaga and Ogata, 2009) investigated the performance of ozone catalytic oxidation of benzene over Mn catalysts with different carriers such as $\mathrm{SiO}_{2}$, $\mathrm{Al}_{2} \mathrm{O}_{3}, \mathrm{TiO}_{2}$, and $\mathrm{ZrO}_{2}$. The results showed that the increased specific surface area of the support can enhance benzene degradation. The high specific surface area does not only facilitate the absorption of pollutants but also prolongs the reaction time between ozone and pollutants.

Transition metals including $\mathrm{Mn}, \mathrm{Fe}, \mathrm{Co}, \mathrm{Cu}, \mathrm{Ni}$, and $\mathrm{Ag}$ were generally used as active components.Among different $\mathrm{Al}_{2} \mathrm{O}_{3}$ supported transition metals, Mn has excellent catalytic activity toward both ozone decomposition and benzene degradation (Einaga and Ogata, 2010). Ebrahim et al. (Rezaeia et al., 2013) studied the effect of Mn loading on ozone catalytic degradation of toluene and found that high Mn loading is detrimental for ozone decomposition and benzene degradation. Despite its potential for efficient pollutant degradation, ozone catalytic oxidation technology is still faced with some problems like the deactivation of catalyst, emission of residual ozone, and generation of byproducts.

\section{VUV-BASED PROCESSES FOR AIR POLLUTANTS DEGRADATION}

\section{Direct VUV Photolysis}

Direct photolysis by Ultraviolet (UV) and Vacuum Ultraviolet (VUV) have been intensively studied for removing both organic and inorganic compounds from water or air. VUV lamp has its main emission at $254 \mathrm{~nm}$ with a small (around 6\%) intensity of irradiation at $185 \mathrm{~nm}$, while UV lamp has its output only at $254 \mathrm{~nm}$ (Alapi and Dombi, 2007a). VUV photolysis is known for better performance on the removal of pollutants based on the following reasons: (1) the high-energy photons generated by $185 \mathrm{~nm}$ irradiation can degrade organic compounds; (2) in the presence of water, $185 \mathrm{~nm}$ irradiation can produce strong oxidants such as hydroxyl radical $(\bullet \mathrm{OH})$; (3) $185 \mathrm{~nm}$ irradiation can generate ozone in the presence of $\mathrm{O}_{2}$ (Yang et al., 2007). Oxygen species [for example, $\mathrm{O}\left({ }^{1} \mathrm{D}\right), \mathrm{O}\left({ }^{3} \mathrm{P}\right)$, and $\mathrm{O}_{3}$ ] and hydroxyl radicals $(\bullet \mathrm{OH})$ are generated by the dissociation of oxygen and water molecules under VUV with high-energy photon according to the following reactions (Bergonzo and Boyd, 1993; Hashem et al., 1997; Fu, 2011; Equations 21-25):

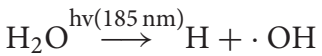

$$
\begin{aligned}
& \mathrm{O}_{2} \stackrel{\mathrm{hv}(185 \mathrm{~nm})}{\longrightarrow} \mathrm{O}\left({ }^{1} \mathrm{D}\right)+\mathrm{O}\left({ }^{3} \mathrm{P}\right) \\
& \mathrm{O}\left({ }^{1} \mathrm{D}\right)+\mathrm{M} \rightarrow \mathrm{O}\left({ }^{3} \mathrm{P}+\mathrm{M}\right)\left(\mathrm{M}=\mathrm{O}_{2} \text { or } \mathrm{N}_{2}\right)
\end{aligned}
$$

$$
\begin{array}{r}
\mathrm{O}\left({ }^{3} \mathrm{P}\right)+\mathrm{O}_{2}+\mathrm{M} \rightarrow \mathrm{O}_{3}+\mathrm{M} \\
\mathrm{O}\left({ }^{1} \mathrm{D}\right)+\mathrm{H}_{2} \mathrm{O} \rightarrow 2 \cdot \mathrm{OH}
\end{array}
$$

These energetic oxidants can be utilized to improve removal efficiencies of the pollutants. It has been proven that VUV photolysis is a more efficient and economical process than the UV photolysis (Huang et al., 2013).

VUV photolysis has also been used in the treatment of wastewater. It has proven to be effective for the treatment of certain types of wastewater pollutants such as fluorescence of phenol, nitrobenzene, SDBS surfactants, Methylene Blue (MB), and other pollutants (Imoberdorf and Mohseni, 2011a,b; Zoschke et al., 2014). Alapi et al. (Alapi and Dombi, 2007a) compared the UV and VUV photolysis of phenol and revealed that the rate of degradation of phenol in the VUV process is about 2 times faster than that in the UV-irradiated process, as shown in Figure 3. Phenol decomposition is initiated by direct photolysis via a biphotonic process in the UV-irradiated solutions, while it can also take place by $\cdot \mathrm{OH}$-based reactions in VUV-irradiated solutions (Alapi and Dombi, 2007a).

Recently, much attempt was made using VUV to degrade air pollutants, such as benzene (Huang H. B. et al., 2014), methylbenzene (Jeong et al., 2006), chlorinated methanes (Alapi and Dombi, 2007b), gaseous $\alpha$-pinene (Chen et al., 2010). Cheng (Cheng, 2011) investigated the photo-degradation of

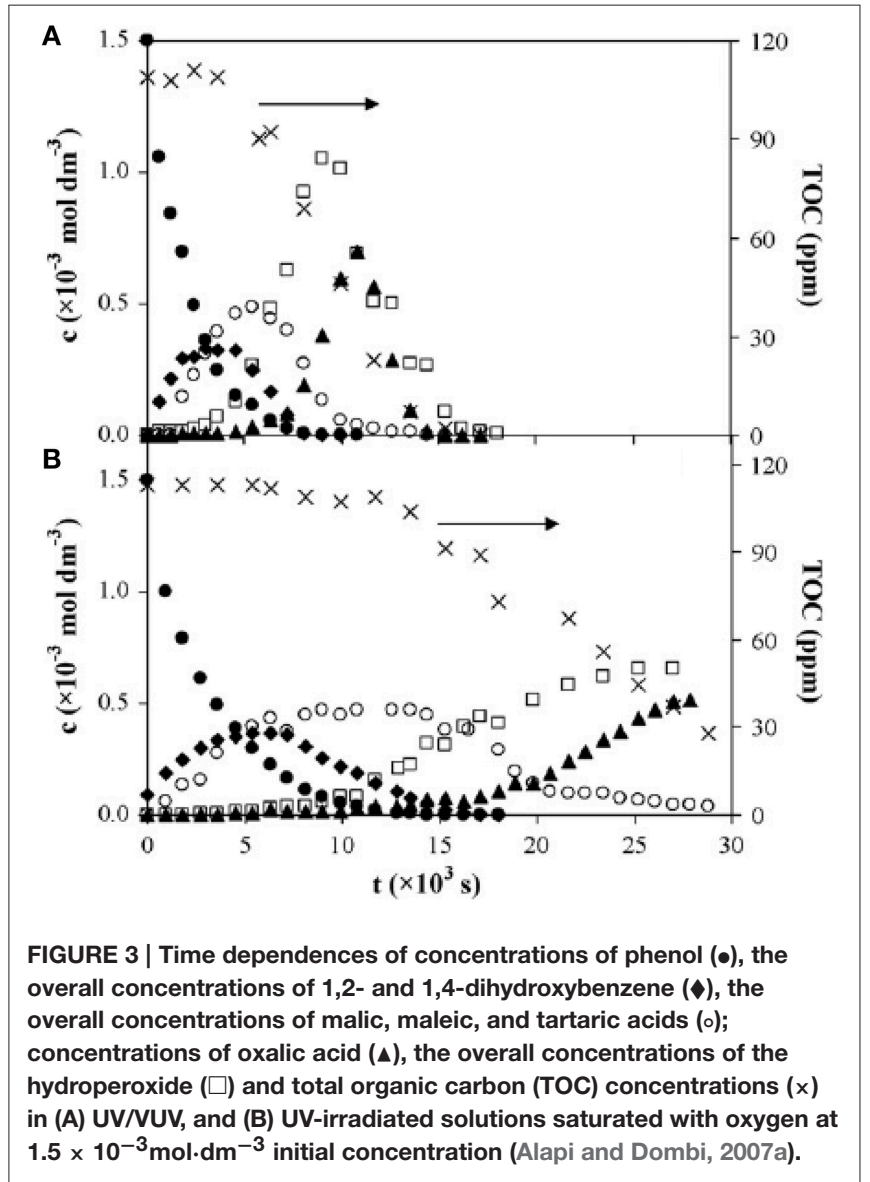


gaseous $\alpha$-pinene by a VUV light. It was discoveredthat most efficient conversion was obtained under the moderate humidity condition. As shown in Figure 4, nearly 100\% conversion efficiency of $\alpha$-pinene was achieved in about 70 s under moderate humidity condition.

Meanwhile, Alapi et al. (Alapi and Dombi, 2007b) investigated the effect of relative humidity and pollutant concentration on the degradation of chlorinated methanes and their mixtures in an oxygen stream under direct VUV photolysis. Chen et al. (2010) used VUV photo-degradation to improve the removal capacity of gaseous $\alpha$-pinene which is hydrophobic and poorly biodegradable. ? investigated the effect of relative humidity, residence time, initial benzene concentration, and reaction temperature on photo-oxidation of gaseous benzene by $185 \mathrm{~nm}$ VUV irradiation. It was discovered that benzene removal efficiency can be greatly improved in the presence of vapor and the formation of hydroxyl radicals is mainly responsible for the degradation. The abovementioned experiments indicated that VUV photolysis is a promising approach to degrade air pollutants.

However, VUV photolysis alone is not effective enough for the total oxidation of organic compounds because of the limited efficiencies that may lead to the formation of organic intermediates (Zhao and Yang, 2003; Alapi and Dombi, 2007a). More importantly, VUV photolysis will generate much toxic $\mathrm{O}_{3}$ (Alapi and Dombi, 2007b; Yang et al., 2007), which is harmful to human health as it causes headaches, throat dryness and damage to mucus membranes at levels as low as 0.1-1 ppm (Huang et al., 2011). Thus, the residual $\mathrm{O}_{3}$ will cause secondary pollution if not removed before emission.

\section{VUV Photolysis-Ozone Catalytic Oxidation (VUV-OZCO)}

Apart from the VUV photolysis, there is another process in the VUV-based processes which has great potential to deal with air pollution. Ozone used for ozone-assisted catalytic oxidation was

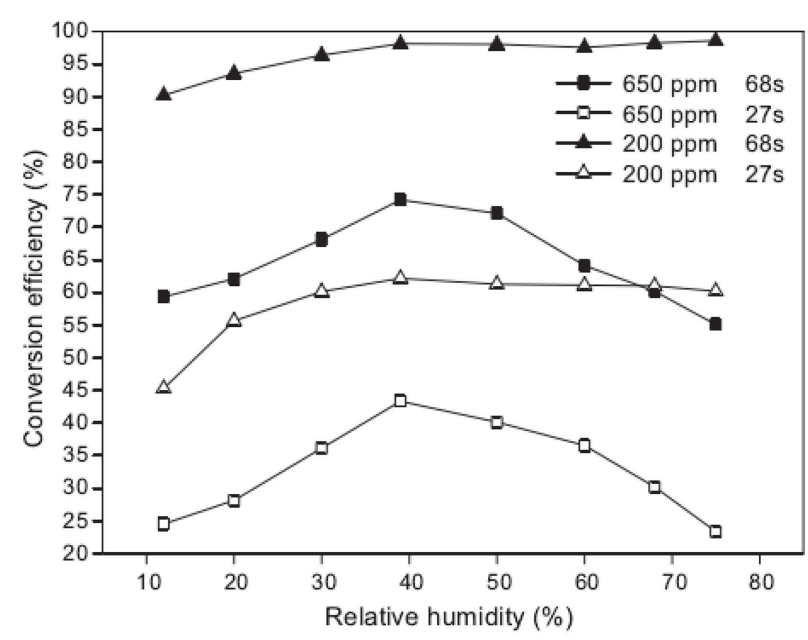

FIGURE 4 | Effect of different humidity on the conversion efficiencies of $\alpha$-pinene photo-degraded in the air (Cheng, 2011). generally generated from high voltage discharge. The cost of this is high and the system is relatively complex. In addition, the degradation efficiency of VUV photolysis alone is low and the residual ozone brings new pollution (Bergonzo and Boyd, 1993; Hashem et al., 1997; Fu, 2011). To avoid the above problems, VUV photolysis can be combined with ozone-assisted catalytic oxidation to make use of the residual ozone and eliminate it. Such a novel process is called VUV-OZCO, in which VOCs would be initially destructed by the VUV photolysis and then be further oxidized by the OZCO using the residual $\mathrm{O}_{3}$ from the VUV photolysis. VUV-OZCO would not only save the cost but also improve the pollutants removal efficiency and eliminate the problem of residual ozone. A possible system of the abovementioned process is shown in Figure 5.

As mentioned above, VUV-OZCO degrades pollutant via two path ways: (1) VUV photolysis; (2) Ozone-assisted catalytic oxidation. The mechanism of VUV photolysis has been described above. The mechanism of catalytic oxidation of ozone varies under different reaction conditions. Under low temperature and low humidity condition, catalytic decomposition of ozone involves two irreversible reactions, that is, the adsorption of ozone and desorption of oxygen atom on the surface of catalyst. The specific processes are as follow (Dhandapani and Oyama, 1997; Li and Oyama, 1998; Equations 26-28):

$$
\begin{array}{r}
\mathrm{O}_{3}+* \rightarrow \mathrm{O}_{2}+\mathrm{O}^{*} \\
\mathrm{O}_{3}+\mathrm{O}^{*} \rightarrow \mathrm{O}_{2}+\mathrm{O}_{2}{ }^{*} \\
\mathrm{O}_{2}^{*} \rightarrow \mathrm{O}_{2}+*
\end{array}
$$

where * is the symbol of the catalyst surface active site.

Under high humidity, the catalyst surface will form a layer of liquid membrane and generate active site by the interaction between metal ions and adsorption liquid membrane. Besides, the liquid film will react with intermediate $\mathrm{O}^{*}$ to generate hydroxyl radicals, which can be used to degrade ozone and pollutants. Some studies have shown that the increased humidity is beneficial to improve the removal efficiency of ozone decomposition and air pollutants. Specific processes are shown in Equations (29-34) (Dhandapani and Oyama, 1997; Einaga and Futamura, 2004b):

$$
\begin{array}{r}
\mathrm{O}_{3}+* \rightarrow \mathrm{O}_{2}+\mathrm{O}^{*} \\
\mathrm{O}_{3}+\mathrm{O}^{*} \rightarrow 2 \mathrm{O}_{2} \\
\mathrm{H}_{2} \mathrm{O}+\mathrm{O}^{*} \rightarrow 2 \mathrm{OH}^{*} \\
\mathrm{OH}^{*}+\mathrm{O}_{3} \rightarrow \mathrm{HO}_{2}^{*}+\mathrm{O}_{2} \\
\mathrm{HO}_{2}^{*}+\mathrm{O}_{3} \rightarrow \mathrm{OH}^{*}+2 \mathrm{O}_{2} \\
\mathrm{HO}_{2}^{*}+\mathrm{OH}^{*} \rightarrow \mathrm{H}_{2} \mathrm{O}+\mathrm{O}_{2}+*
\end{array}
$$

Under certain humidity, ozone catalytic oxidation uses highly reactive intermediates $\mathrm{O}^{*}, \mathrm{O}_{2}^{*}$, and $\cdot \mathrm{OH}$ to degrade organic pollutants (Equations 35-37).

$$
\begin{array}{r}
\mathrm{R}+* \rightarrow \mathrm{R}^{*} \\
\mathrm{R}^{*}+\mathrm{O}^{*} \rightarrow \mathrm{CO}+\mathrm{CO}_{2} \\
\mathrm{R}^{*}+\mathrm{OH}^{*} \rightarrow \mathrm{H}_{2} \mathrm{O}+\mathrm{CO}_{2}
\end{array}
$$


where $\mathrm{R}$ represents the pollutant to be degraded.

Huang et al. (Huang, 2015) firstly developed this system to degrade VOCs and studied its performance and mechanism. The results show that both benzene and $\mathrm{O}_{3}$ are completely removed by VUV-OZCO with Mn/ZSM-5 catalysts. As a new technology, few studies have been carried out using VUV-OZCO for air pollution control. However, it provides an efficient and promising process for the degradation of VOCs. This VUV-OZCO process would not only improve the degradation and the mineralization rate, but it will also remove residual ozone.

\section{Photocatalytic Oxidation under VUV Irradiation (VUV-PCO) VUV-PCO without Ozone Oxidation}

Besides the emission of by-products such as ozone, VUV photolysis alone will cause wastage of the UV energy since only $185 \mathrm{~nm}$ VUV irradiation can be directly used to destruct the air pollutants while the $254 \mathrm{~nm}$ UV irradiation, which is the main emission of the VUV lamps, is not utilized. To fully make use of the UV irradiation, photocatalysts were introduced into the VUV photolysis process. Such process is called VUV-PCO process. A possible installation of the VUV-PCO system is shown in Figure 6.

It is well known that conventional PCO has some disadvantages, such as catalyst deactivation (Peral and Ollis, 1997; Cao et al., 2000), low degradation rate (Mo et al., 2009), formation of toxic byproducts (Huang and Li, 2011), recombination of electron-hole pair, and low efficiency (Mo et al., 2009; Huang and Li, 2011). It has proven that VUV-PCO can obviously improve the efficiency and stability performance of PCO of pollutants and reduce the generation of intermediates (Zhang and Liu, 2004; Yu and Lee, 2007; Huang et al., 2009; Huang and Li, 2011). Huang et al. (2011) compared the VUV, VUV-PCO, UV-PCO processes for toluene destruction. Results showed that the toluene removal efficiency in the VUV-PCO process was 7 times more than that in the UV-PCO process, and no obvious deactivation was observed in the former, as shown in Figure 7.

Compared with VUV photolysis, toluene removal was greatly improved. Meanwhile, both the organic compounds and ozone were significantly reduced. In contrast with the UV-PCO, the VUV-PCO can destruct pollutants with more pathways, besides UV-PCO and UV photolysis (Huang et al.,

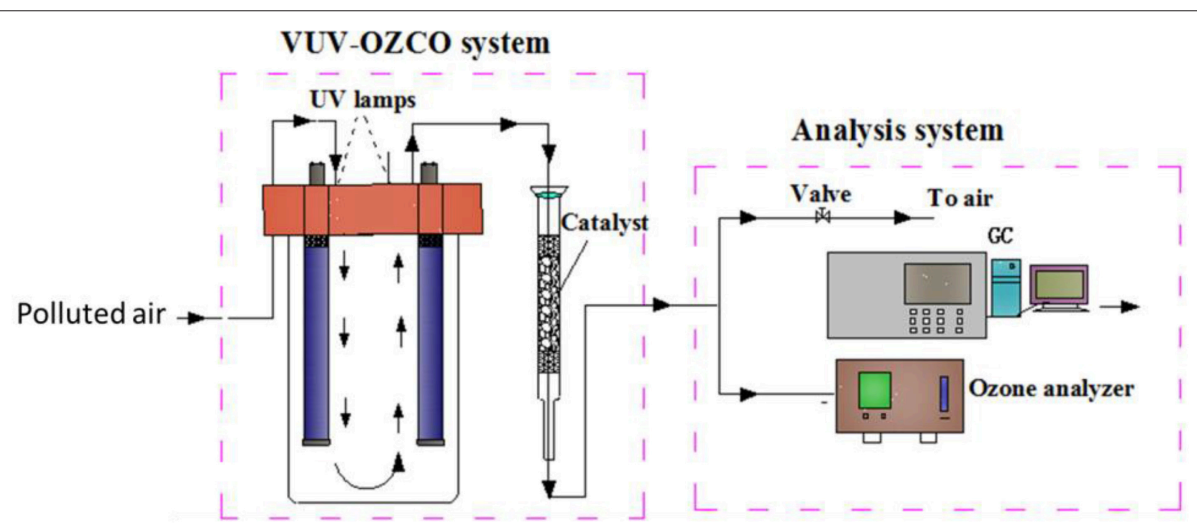

FIGURE 5 | The schematic diagram of VUV-OZCO system (Huang, 2015).

\section{VUV-PCO system}

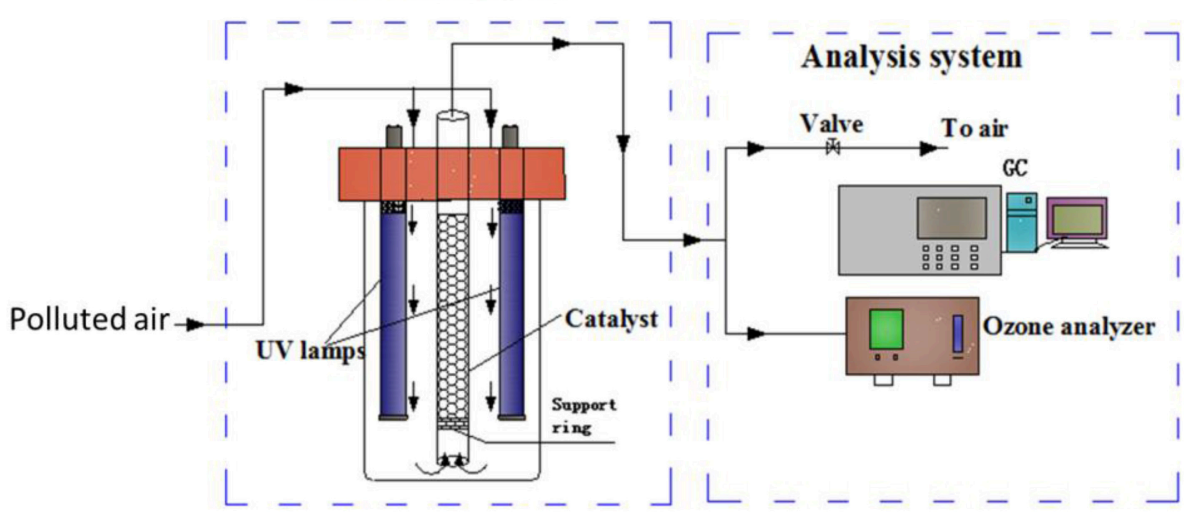

FIGURE 6 | Schematic diagram of a VUV-PCO system (Huang et al., 2015a). 


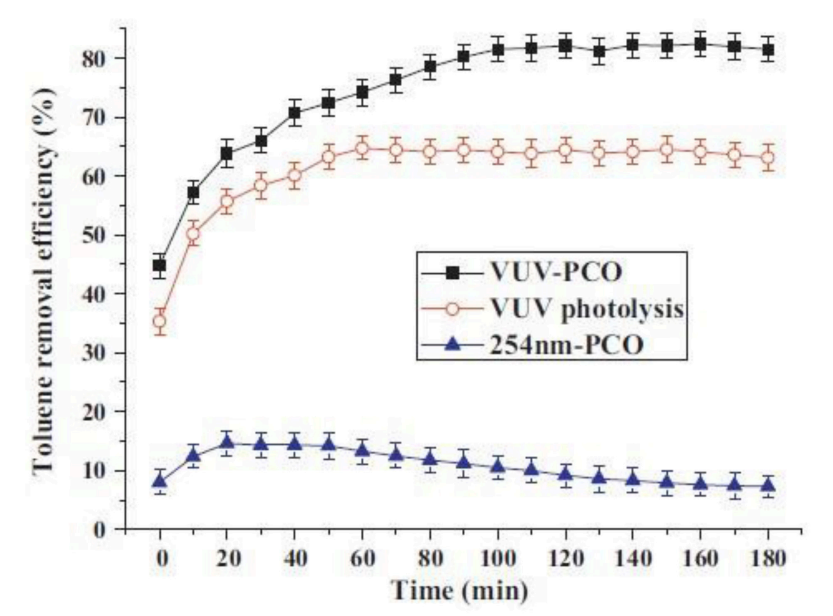

FIGURE 7 | Toluene removal efficiency in different processes (Huang et al., 2011).

2011, 2015a). Ozone has a strong electro-negativity, which improves the ability to capture the photon-generated electrons to produce hydroxyl radicals (Huang et al., 2009; Huang and Li, 2011). Meanwhile, ozone can inhibit the combination between electronics and electronic acupuncture point to improve the photoluminescence efficiency (Huang et al., 2009; Huang and $\mathrm{Li}, 2011) \cdot \mathrm{O}_{3}$ is a byproduct from the VUV lamp, which is also a strong oxidizing agent. Although ozone alone cannot directly oxidize refractory VOCs such as benzene and toluene, it can be decomposed into highly active oxygen through catalytic decomposition for VOCs oxidation (Huang et al., 2015a).

\section{VUV-PCO with Ozone Oxidation}

Despite the fact that ozone can help to decompose the VOCs, it can only be partially decomposed and utilized since most of the photocatalysts developed have limited activity toward ozone decomposition (Jeong et al., 2004). The residual ozone still posesa great challenge to achieve a good solution of free secondary pollution. Recently, modified photocatalysts were studied to further eliminate $\mathrm{O}_{3}$ efficiently while enhancing the removal performance of VOCs.

In the study of $\mathrm{Fu}$ (2014), Pt modified $\mathrm{TiO}_{2}$ was used to degrade gaseous formaldehyde and $\mathrm{O}_{3}$ byproduct under the $\mathrm{UV}, \mathrm{UV}+\mathrm{O}_{3}$, and VUV-PCO processes. The FE-SEM image of $\mathrm{TiO}_{2}$ film modified with $\mathrm{Pt}$ nanoparticles is shown in Figure 8. It was discovered that $\sim 4-8 \mathrm{Pt}$ nanoparticles (NPs) were deposited onto each $\mathrm{TiO}_{2}$ particle and this uniform dispersion of $\mathrm{Pt}(\mathrm{NPs})$ was beneficial for increasing the amount of reactive sites and metal- $\mathrm{TiO}_{2}$ contact area, which result in better performance of $\mathrm{HCHO}$ degradation. The above experiments showed that the degradation rate of $\mathrm{HCHO}$ decreases in the order of $\mathrm{VUV}>\mathrm{O}_{3}+\mathrm{UV} 254 \mathrm{~nm}>\mathrm{UV} 254 \mathrm{~nm}$ for both photocatalysts studied, as indicated in Figure 9. In addition, in the VUV-PCO process, $\mathrm{O}_{3}$ is utilized to strengthen the efficiency of PCO of VOCs.

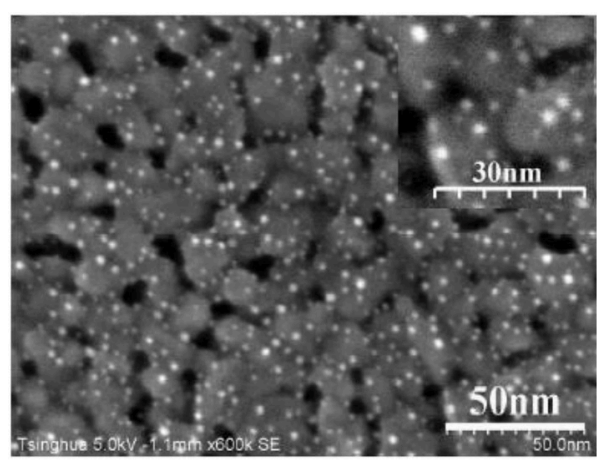

FIGURE 8 | Ultra high-resolution FESEM image of $\mathrm{TiO}_{2}$ film modified with Pt nanoparticles (Fu, 2014).

Meanwhile, Kim (Kim et al., 2014) deposited palladium nanoparticles onto $\mathrm{TiO}_{2}$ film for simultaneous removal of toluene and ozone byproduct. Compared with the direct VUV photolysis and the $\mathrm{TiO}_{2} / \mathrm{VUV}$ photocatalytic processes, $\mathrm{Pd}-\mathrm{TiO}_{2} / \mathrm{VUV}$ process exhibited a better performance toward toluene degradation and $90 \%$ of the ozone generated by the $185 \mathrm{~nm}$ VUV photolysis was simultaneously degraded, as shown in Figure 10. Immersion time reflects to the time that he immersed the $\mathrm{TiO}_{2}$ film into a palladium colloid solution in order to deposit palladium nanoparticles onto the $\mathrm{TiO} 2$ film.

Huang et al. (2015a) prepared $\mathrm{TiO}_{2}$ modified by transition metals ( $\mathrm{Mn}, \mathrm{Co}, \mathrm{Cu}, \mathrm{Ni}$, and $\mathrm{Fe}$ ) for studying the PCO of gaseous benzene under VUV irradiation. They found that the PCO efficiency of benzene under VUV irradiation reached 58\%, which is over 20 times higher than that under $254 \mathrm{~nm}$ UV irradiation, as shown in Table 1. In addition, ozone can be completely eliminated by $\mathrm{MnO}_{2} / \mathrm{TiO}_{2}$.

Compared to UV-PCO and VUV, VUV-PCO showed higher performance, less byproducts and better stability during VOCs oxidation. Among the multiple pathways in VUV-PCO, photolysis, and catalytic ozonation played a dominant role in VOCs destruction while the contribution of UV-PCO is relatively low, as shown in Table 1 (Huang et al., 2015a). More efforts should be made to develop efficient materials with excellent photocatalytic activity and superior capacity for ozone decomposition. Although the stability of VUV-PCO was greatly increased compared to UV-PCO, VUV-PCO still faces the challenge of catalytic deactivation due to the accumulation of organic intermediates and water vapor on the surface (Quici et al., 2010). Thus, how to inhibit catalyst deactivation and increase the stability poses another challenge in the VUV-PCO process.

The porous support may be a way to solve the deactivation problem and increase the efficiency of degradation. Yuan et al. (2013) have used H-ZSM-5 as the photocatalyst support to generate the $\mathrm{TiO}_{2} / \mathrm{M}-\mathrm{ZSM}-5$ catalyst $(\mathrm{M}=\mathrm{Zn}, \mathrm{Cu}, \mathrm{Mn})$. The prepared samples were used as catalyst for degradation of gaseous acetaldehyde in the presence of $\mathrm{UV}$ light irradiation, $\mathrm{O}_{3}$ or $\mathrm{UV}-\mathrm{O}_{3} \cdot \mathrm{TiO}_{2} / \mathrm{Mn}-\mathrm{ZSM}-5$ presents the highest activity with acetaldehyde degradation rate of 78.9\%, as shown in Figure 11. 

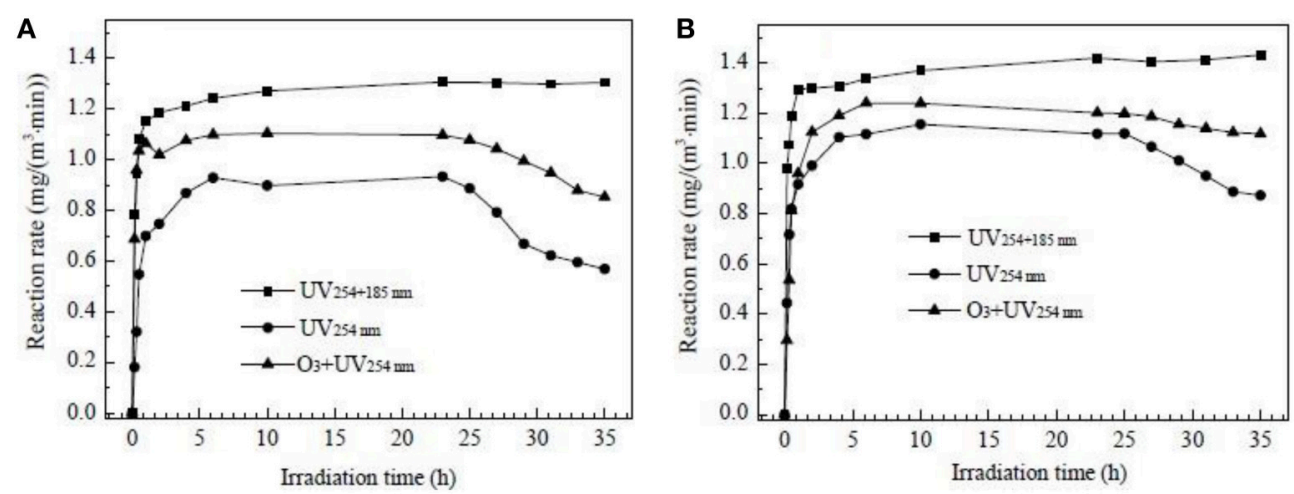

FIGURE 9 | Degradation rate of formaldehyde as a function of irradiation time under UV254, $\mathrm{O}_{3}+\mathrm{UV254}$, and UV254+185 nm irradiation over pure TiO ${ }_{2}$ (A) and $\mathrm{Pt}^{-\mathrm{TiO}_{2}}$ films (B) (Fu, 2014).

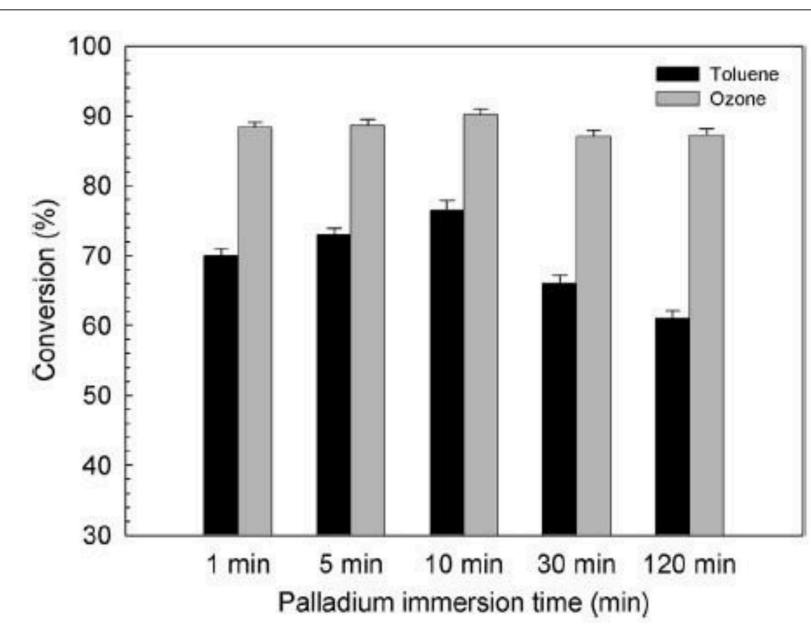

FIGURE 10 | Effect of the immersion time on the activity of $\mathrm{Pd}-\mathrm{TiO}_{2}$ films to degrade toluene and ozone under VUV irradiation (Kim et al., 2014).

TABLE 1 | Contribution of various sub-processes to benzene removal (Huang et al., 2015a).

\begin{tabular}{lccccccc}
\hline & $\mathbf{M n}_{\mathbf{T i O}} \mathbf{2}$ & $\mathbf{C u} / \mathrm{TiO}_{2}$ & $\mathbf{C o} / \mathbf{T i O}_{2}$ & $\mathbf{N i} / \mathrm{TiO}_{2}$ & $\mathbf{P 2 5}$ & $\mathbf{F e} / \mathrm{TiO}_{2}$ & $\mathbf{T i O}_{2}$ \\
\hline VUV-PCO, \% & 58 & 50.9 & 51.5 & 50.3 & 50.2 & 45.3 & 45.7 \\
VUV, \% & 38 & 38 & 38 & 38 & 38 & 38 & 38 \\
UV-PCO, \% & 2.4 & 1.2 & 2.1 & 1.5 & 2 & 0.8 & 1.6 \\
Catalytic & 17.6 & 11.7 & 11.4 & 10.8 & 10.2 & 6.5 & 6.1 \\
Ozonation, \% & & & & & & &
\end{tabular}

The superior performance results from the coupling effect of photocatalytic and ozone oxidation.

Porous material like ZSM-5 can adsorb the pollutants so that it can prolong the reaction time of photocatalysis and ozone catalytic oxidation thereby improving the efficiency of degradation of pollutants. With its intensive oxidation performance, it will accumulate less intermediates thereby solving the problem of deactivation. Therefore, further research

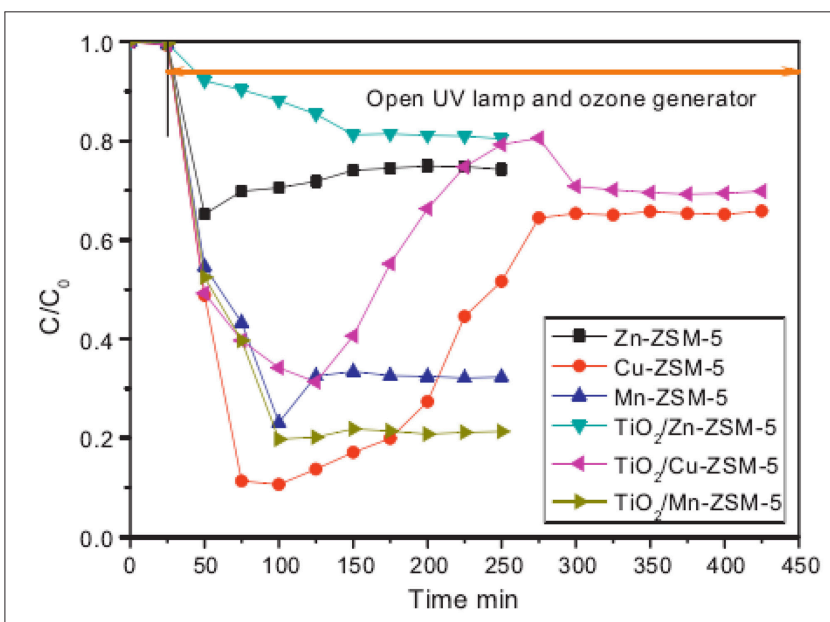

FIGURE 11 | Degradation of acetaldehyde on M-ZSM-5 and $\mathrm{TiO}_{2} / \mathrm{M}-\mathrm{ZSM}-5$ under UV-ozone (UV main wavelength, $254 \mathrm{~nm}$; inlet concentration of $\mathrm{CH} 3 \mathrm{CHO}, 269 \mathrm{ppm}$; space velocity, 67,000 $\mathrm{h}^{-1}$; inlet concentration of ozone, 131 ppm) (Yuan et al., 2013).

on VUV-based process in the future should adopt this catalyst and find out its potential.

\section{OUTLOOKS IN VUV-BASED PROCESSES FOR AIR POLLUTANTS DEGRADATION}

To increase the utilization of VUV irradiation and the residual ozone, VUV-OZCO, and VUV-PCO with ozone oxidation should be focused on, in further study. More attention should be paid on:

(1) Catalytic deactivation. Catalyst deactivation is mainly caused by water deposition and the accumulation of intermediates on the surface of catalysts (Gandhi et al., 2012). It may be solved by hydrophobic catalysts (Zhao and Lu, 1998; Kuwahara et al., 2009) and by metal doping on the catalysts to improve the rate of mineralization and oxidation ability (Qi and Yang, 2004; Wang et al., 2012; Yang et al., 2014). 
(2) Mechanism study. VUV-PCO is an emerging process for VOCs degradation and few works were carried out. The mechanism of it is still unclear, which prevent making the best use of it for air pollution control. Therefore, further study should be continued to find out the relationship between VUV photolysis, photocatalysis, and ozone oxidation.

(3) Immobilization of the catalysts (Lei et al., 2009). Most of the catalysts developed are powder or particle catalysts. They cannot be widely used in the industry since it is hard to be reused and regenerated. It is necessary to develop supported catalysts such as honeycomb.

\section{SUMMARY}

VUV-based process is an emerging technology. It is very efficient for pollutants degradation as compared with conventional process. The development of VUV-based processes has provided new direction for the generation of reactive hydroxyl radicals for pollution degradation (Chih-Ming et al., 2011).

The technology mainly involves three processes that can efficiently degrade organic compounds: direct photolysis, photocatalysis, and ozone oxidation produced by the by-product ozone. In this paper, the generation of the active groups and the effect of active group are reviewed. By producing hydroxyl radicals, these three kinds of effects can all result in fast degradation of organic matter, despite they act alone or together. The combination of the three processes enhances the oxidation and offers many opportunities in the air pollution treatment.

Although, only a few practical applications of VUV-based processes have so far been carried out this technology has

\section{REFERENCES}

Aizpuru, A., Malhautier, L., Roux, J.-C., and Fanlo, J.-L. (2001). Biofiltration of a mixture of volatile organic emissions. Waste Manag. Assoc. 51, 1662-1670. doi: 10.1080/10473289.2001.10464388

Alapi, T., and Dombi, A. (2007a). Comparative study of the UV and UV/VUV-induced photolysis of phenol in aqueous solution. J. Photochem. Photobiol. A 188, 409-418. doi: 10.1016/j.jphotochem.2007. 01.002

Alapi, T., and Dombi, A. (2007b). Direct VUV photolysis of chlorinated methanes and their mixtures in an oxygen stream using an ozone producing low-pressure mercury vapour lamp. Chemosphere 67, 693-701. doi: 10.1016/j.chemosphere.2006.10.066

Atkinson, R., Baulch, D. L., Cox, R. A., Crowley, J. N., Hampson, R. F., Hynes, R. G., et al. (2004). Evaluated Kinetic and Photochemical Data for Atmospheric Chemistry: Volume I - Gas Phase Reactions of Ox, HOx, NOx and SOx Species. Copernicus GmbH.

Atkinson, R., Baulich, D. L., Cox, R. A., Crowley, J. N., Hampson, R. F., Kerr, J. A., et al. (1996). Summary of evaluated kinetic and photochemical data for atmospheric chemistry iupac subcommittee on gas kinetic data evaluation for atmospheric chemistry. Atmos. Environ. 30, 3903-3904. doi: 10.1016/13522310(96)87633-3

Baker, R. W., Simmons, V. L., Kaschemekat, J., and Wijmans, J. G. (1994). Membrane systems for VOC recovery from air streams. Separation 31, 231-235. doi: 10.1016/0015-1882(94)80376-5

Barbero, B. P., Costa-Almeida, L., Sanz, O., Morales, M. R., Cadus, L. E., and Montes, M. (2008). Washcoating of metallic monoliths great potential for air pollution control. Unlike water treatment, there is no need to worry about the low penetration of the VUV light, which is the main technical limitation on waste-water treatment. VUV irradiation will not be strongly limited by the pollutant molecules and the particles compared with the wastewater treatment. Therefore, it can improve the efficiency of the VUV lamp. In addition, existing problems of the VUV-based processes include the catalyst deactivation and the unclear degradation mechanism and the immobilization of catalyst. It is anticipated that these problems can be solved in future for efficient utilization of the process in the industry.

\section{AUTHOR CONTRIBUTIONS}

Haibao Huang was in the charge of writing the review paper. HL and LW were in the charge of VUV-based processes for air pollutants degradation. Huiling Huang and JZ were in the charge of introduction and generation of the oxidants. DL was in the charge of outlooks and summary.

\section{ACKNOWLEDGMENTS}

The authors gratefully acknowledge the financial supports from National Nature Science Foundation of China (No. 51208207), Doctoral Program of Higher Education of China (No. 20120172120039), Key Science and Technology Project in Guangzhou (No. 2014Y2-00094) and Guangdong (No. 2015B020236004), NSFC-RGC (No. 51561165015, No. N_HKU718/15), and the Key Fundamental Research Funds for the Central Universities (15lgjc07).

with a $\mathrm{MnCu}$ catalyst for catalytic combustion of volatile organic compounds. Chem. Eng. J. 139, 430-435. doi: 10.1016/j.cej.2007. 12.033

Bergonzo, P., and Boyd, I. W. (1993). Low pressure photodeposition of silicon nitride films using a xenon excimer lamp. Appl. Phys. Lett. 63, 1757-1759. doi: 10.1063/1.110705

Bolton, J. R., and Denkewicz, R. (2008). Synergistic Disinfection of Drinking Water Using Ultraviolet and Ozone Co-generated from the Same UV Lamp. World Water Congress on Ozone and Ultraviolet Technologies.

Brito, J., Wurm, F., Yanez-Serrano, A. M., de Assuncao, J. V., Godoy, J. M., and Artaxo, P. (2015). Vehicular emission ratios of VOCs in a megacity impacted by extensive ethanol use: results of ambient measurements in Sao Paulo, Brazil. Environ. Sci. Technol. 49, 11381-11387. doi: 10.1021/acs.est.5 b03281

Cao, L. X., Gao, Z., and Suib, S. L. (2000). Photocatalytic oxidation of toluene on nanoscale $\mathrm{TiO}_{2}$ catalysts: studies of deactivation and regeneration. Am. Chem. Soc. 220, 269. doi: 10.1006/jcat.2000.3050

Chen, J. M., Cheng, Z. W., Jiang, Y. F., and Zhang, L. L. (2010). Direct VUV photodegradation of gaseous alpha-pinene in a spiral quartz reactor: intermediates, mechanism, and toxicity/biodegradability assessment. Chemosphere 81, 1053-1060. doi: 10.1016/j.chemosphere.2010. 09.060

Cheng, Z.-W. (2011). Conversion characteristics and kinetic analysis of gaseous $\alpha$ pinene degraded by a VUV light in various reaction media. Sep. Purif. Technol. 77, 26-32. doi: 10.1016/j.seppur.2010.11.014

Chih-Ming, M., Gui-Bing, H., Hua-Wei, C., Nguyen-Thi, H., and Yung-Shuen, S. (2011). Photooxidation contribution study on the decomposition of Azo dyes 
in aqueous solutions by VUV-based AOPs. Int. J. Photoenergy 2011:156456. doi: $10.1155 / 2011 / 156456$

Daifullah, A. A. M., and Girgis, B. S. (2003). Impact of surface characteristics of activated carbon on adsorption of BTEX. Colloids Surf. A 214, 181-193. doi: $10.1016 /$ S0927-7757(02)00392-8

Daniels, S. L. (2002). "On the ionization of air for removal of noxious effluvia" (Air ionization of indoor environments for control of volatile and particulate contaminants with nonthermal plasmas generated by dielectric-barrier discharge). IEEE Trans. Plasma Sci. 30, 1471-1481. doi: 10.1109/TPS.2002.804211

Deshusses, M. A., and Johnson, C. T. (2000). Development and validation of a simple protocol to rapidly determine the performance of biofilters for VOC treatment. Technology 34, 461-467. doi: 10.1021/es9909172

Dhandapani, B., and Oyama, S. T. (1997). Gas phase ozone decomposition catalysts. Appl. Catal. B 11, 129-166. doi: 10.1016/S0926-3373(96)00044-6

Dulin, J. M., and Rosar, E. C. (1975). Air Pollution Control Process for Glass Manufacture (Chicago, IL: Industrial Resources, Inc.).

Einaga, H., and Futamura, S. (2004a). Comparative study on the catalytic activities of alumina-supported metal oxides for oxidation of benzene and cyclohexane with ozone. React. Kinet. Catal. Lett. 81, 121-128. doi: 10.1023/B:REAC.0000016525.91158.c5

Einaga, H., and Futamura, S. (2004b). Catalytic oxidation of benzene with ozone over alumina-supported manganese oxides. J. Catal. 227, 304-312. doi: 10.1016/j.jcat.2004.07.029

Einaga, H., and Futamura, S. (2005). Oxidation behavior of cyclohexane on alumina-supported manganese oxides with ozone. Appl. Catal. B 60, 49-55. doi: 10.1016/j.apcatb.2005.02.017

Einaga, H., Harada, M., and Ogata, A. (2009). Relationship between the structure of manganese oxides on alumina and catalytic activities for benzene oxidation with ozone. Catal. Lett. 129, 422-427. doi: 10.1007/s10562-008-9814-9

Einaga, H., and Ogata, A. (2009). Benzene oxidation with ozone over supported manganese oxide catalysts: effect of catalyst support and reaction conditions. J. Hazard. Mater. 164, 1236-1241. doi: 10.1016/j.jhazmat.2008.09.032

Einaga, H., and Ogata, A. (2010). Catalytic oxidation of benzene in the gas phase over alumina-supported silver catalysts. Environ. Sci. Technol. 44, 2612-2617. doi: $10.1021 /$ es 903095 j

Einaga, H., Teraoka, Y., and Ogata, A. (2013). Catalytic oxidation of benzene by ozone over manganese oxides supported on USY zeolite. J. Catal. 305, 227-237. doi: 10.1016/j.jcat.2013.05.016

Fu, P. (2011). Photocatalytic degradation of low concentration formaldehyde and simultaneous elimination of ozone by-product using palladium modified $\mathrm{TiO}_{2}$ films under UV254+185nm irradiation. Appl. Catal. B 105, 220-228. doi: 10.1016/j.apcatb.2011.04.021

$\mathrm{Fu}$, P. (2014). Characterization of $\mathrm{Pt}-\mathrm{TiO}_{2}$ film used in three formaldehyde photocatalytic degradation systems UV254 nm, $\mathrm{O}_{3}+\mathrm{UV}_{254 \mathrm{~nm}}$ and $\mathrm{UV}_{254+185 \mathrm{~nm}}$ via X-ray photoelectron spectroscopy. Chin. J. Catal. 35, 210-218. doi: 10.1016/S1872-2067(12)60740-2

Fu, P., Zhang, P., and Li, J. (2011). Photocatalytic degradation of low concentration formaldehyde and simultaneous elimination of ozone by-product using palladium modified $\mathrm{TiO}_{2}$ films under $\mathrm{UV}_{254+185 \mathrm{~nm}}$ irradiation. Appl. Catal. B 105, 220-228. doi: 10.1016/j.apcatb.2011.04.021

Gandhi, V. G., Mishra, M. K., and Joshi, P. A. (2012). A study on deactivation and regeneration of titanium dioxide during photocatalytic degradation of phthalic acid. J. Ind. Eng. Chem. 18, 1902-1907. doi: 10.1016/j.jiec.2012.05.001

Gonzalez, M., Oliveros, E., Worner, M., and Braun, A. (2004). Vacuum-ultraviolet photolysis of aqueous reaction systems. J. Photochem. Photobiol. C 5, 225-246. doi: 10.1016/j.jphotochemrev.2004.10.002

Hashem, T., Zirlewagen, M., and Braun, A. (1997). Simultaneous photochemical generation of ozone in the gas phase and photolysis of aqueous reaction systems using one VUV light source. Water Sci. Technol. 35, 41-48. doi: $10.1016 /$ S0273-1223(97)00007-3

Huang, H. (2015). "Efficient degradation of gaseous benzene by VUV photolysis combined with ozone-assisted catalytic oxidation: performance and mechanism," in The 7th China- Japan Workshop on Environmental Catalysis and Eco-Materials (Guangzhou).

Huang, H., Huang, H., Zhang, L., Hu, P., Xu, Y., Ye, X., et al. (2014). Photooxidation of gaseous benzene by $185 \mathrm{~nm}$ VUV irradiation. Environ. Eng. Sci. 31, 481-486. doi: 10.1089/ees.2014.0100
Huang, H., Huang, H., Zhang, L., Hu, P., Ye, X., and Leung, D. Y. C. (2015a). Enhanced degradation of gaseous benzene under vacuum ultraviolet (VUV) irradiation over $\mathrm{TiO}_{2}$ modified by transition metals. Chem. Eng. J. 259, 534-541. doi: 10.1016/j.cej.2014.08.057

Huang, H., Leung, D. Y. C., Kwong, P. C. W., Xiong, J., and Zhang, L. (2013). Enhanced photocatalytic degradation of methylene blue under vacuum ultraviolet irradiation. Catal. Today 201, 189-194. doi: 10.1016/j.cattod.2012.06.022

Huang, H., Leung, D. Y. C., Li, G., Leung, M. K. H., and Fu, X. (2011). Photocatalytic destruction of air pollutants with vacuum ultraviolet (VUV) irradiation. Catal. Today 175, 310-315. doi: 10.1016/j.cattod.2011.04.015

Huang, H., and Li, W. (2011). Destruction of toluene by ozone-enhanced photocatalysis: performance and mechanism. Appl. Catal. B 102, 449-453. doi: 10.1016/j.apcatb.2010.12.025

Huang, H., Xu, Y., Feng, Q., and Leung, D. Y. C. (2015b). Low temperature catalytic oxidation of volatile organic compounds: a review. Catal. Sci. Technol. 5, 2649-2669. doi: 10.1039/C4CY01733A

Huang, X., Yuan, J., Shi, J., and Shangguan, W. (2009). Ozone-assisted photocatalytic oxidation of gaseous acetaldehyde on $\mathrm{TiO}_{2} / \mathrm{H}-\mathrm{ZSM}-5$ catalysts. J. Hazard. Mater. 171, 827-832. doi: 10.1016/j.jhazmat.2009.06.070

Imoberdorf, G., and Mohseni, M. (2011a). Modeling and experimental evaluation of vacuum-UV photoreactors for water treatment. Chem. Eng. Sci. 66, 1159-1167. doi: 10.1016/j.ces.2010.12.020

Imoberdorf, G., and Mohseni, M. (2011b). Degradation of natural organic matter in surface water using vacuum-UV irradiation. J. Hazard. Mater. 186, 240-246. doi: 10.1016/j.jhazmat.2010.10.118

Järnström, H., Saarela, K., Kalliokoski, P., and Pasanen, L. A. (2006). Reference values for indoor air pollutant concentrations in new, residential buildings in Finland. Atmos. Environ. 40, 7178-7191. doi: 10.1016/j.atmosenv.2006.06.021

Jeong, J., Sekiguchi, K., and Sakamoto, K. (2004). Photochemical and photocatalytic degradation of gaseous toluene using short-wavelength UV irradiation with $\mathrm{TiO}_{2}$ catalyst: comparison of three UV sources. Chemosphere 57, 663-671. doi: 10.1016/j.chemosphere.2004.05.037

Jeong, J., Sekiguchi, K., Saito, M., Lee, Y., Kim, Y., and Sakamoto, K. (2006). Removal of gaseous pollutants with a UV-C $254+185 \mathrm{~nm} / \mathrm{TiO}_{2}$ irradiation system coupled with an air washer. Chem. Eng. J. 118, 127-130. doi: 10.1016/j.cej.2005.11.020

Jiang, Z., Chen, M., Shi, J., Yuan, J., and Shangguan, W. (2015). Catalysis removal of indoor volatile organic compounds in room temperature:from photocatalysis to active species assistance catalysis. Catal. Surv. Asia 19, 1-16. doi: 10.1007/s10563-014-9177-8

Kim, J., Zhang, P., Li, J., Wang, J., and Fu, P. (2014). Photocatalytic degradation of gaseous toluene and ozone under UV254+185 nm irradiation using a Pddeposited $\mathrm{TiO}_{2}$ film. Chem. Eng. J. 252, 337-345. doi: 10.1016/j.cej.2014. 05.015

Konova, P., Stoyanova, M., Naydenov, A., Christoskova, S., and Mehandjiev, D. (2006). Catalytic oxidation of VOCs and CO by ozone over alumina supported cobalt oxide. Appl. Catal. A 298, 109-114. doi: 10.1016/j.apcata.2005.09.027

Konstantinou, I. K., and Albanis, T. A. (2004). $\mathrm{TiO}_{2}$-assisted photocatalytic degradation of azo dyes in aqueous solution: kinetic and mechanistic investigations. Appl. Catal. B 49, 1-14. doi: 10.1016/j.apcatb.2003. 11.010

Kutschera, K., Bornick, H., and Worch, E. (2009). Photoinitiated oxidation of geosmin and 2-methylisoborneol by irradiation with $254 \mathrm{~nm}$ and $185 \mathrm{~nm} \mathrm{UV}$ light. Water Res. 43, 2224-2232. doi: 10.1016/j.watres.2009.02.015

Kuwahara, Y., Maki, K., Matsumura, Y., Kamegawa, T., Mori, K., and Yamashita, H. (2009). Hydrophobic modification of a mesoporous silica surface using a fluorine-containing silylation agent and its application as an advantageous host material for the $\mathrm{TiO}_{2}$ photocatalyst. Ind. Eng. Chem. Res. 113, 1552-1559. doi: 10.1021/jp809191v

Kwong, C. W., and Chao, C. Y. H. (2010). Fly-ash products from biomass co-combustion for VOC control. Bioresour. Technol. 101, 1075-1081. doi 10.1016/j.biortech.2009.09.008

Lee, B. (1991). Highlights of the clean air act amendments off 1990. Waste Manag. Assoc. 41, 16-19. doi: 10.1080/10473289.1991.10466820

Lei, Z., Liu, X., and Jia, M. (2009). Modeling of Selective Catalytic Reduction (SCR) for NO removal using monolithic honeycomb catalyst. Energy Fuels 23, 6146-6151. doi: 10.1021/ef900713y 
Li, W., and Oyama, S. T. (1998). Mechanism of ozone decomposition on a manganese oxide catalyst. 2. Steady-state and transient kinetic studies. J. Am. Chem. Soc. 120, 9047-9052. doi: 10.1021/ja9814422

Li, W. B., Wang, J. X., and Gong, H. (2009). Catalytic combustion of VOCs on non-noble metal catalysts. Catal. Today 148, 81-87. doi: 10.1016/j.cattod.2009.03.007

Linsebigler, A. L., Lu, G., and Yates, J. T. (1995). Photocatalysis on $\mathrm{TiO}_{2}$ surfaces: principles, mechanisms, and selected results. Chem. Rev. 95, 735-758. doi: $10.1021 / \mathrm{cr} 00035 \mathrm{a} 013$

Lopez, J. L., Einschlag, F. S. G., González, M. C., Capparellia, A. L., Oliveros, E., Hashemet, T. M., et al. (2000). Hydroxyl radical initiated photodegradation of 4-chloro-3,5-dinitrobenzoic acid in aqueous solution. J. Photochem. Photobiol. A 137, 177-184. doi: 10.1016/S1010-6030(00)00357-9

Lu, C., Chu, W., and Lin, M.-R. (2000). Removal of BTEX vapor from waste gases by a trickle bed biofilter. Waste Manag. Assoc. 50, 411-417. doi: 10.1080/10473289.2000.10464021

Masschelein, W. J., and Rice, R. G. (2002). Ultraviolet Light in Water and Wastewater Sanitation (Boca Raton, FL: CRC Press).

McGwin, G. Jr., Lienert, J., and Kennedy, J. I., Jr. (2010). Formaldehyde exposure and asthma in children: a systematic review. Environ. Health Perspect. 118, 313-317. doi: 10.1289/ehp.0901143

Mo, J., Zhang, Y., Xu, Q., Zhu, Y., Lamson, J. J., and Zhao, R. (2009). Determination and risk assessment of by-products resulting from photocatalytic oxidation of toluene. Appl. Catal. B 89, 570-576. doi: 10.1016/j.apcatb.2009.01.015

Moretti, E. C. (2002). Reduce VOC and HAP emissions. Chem. Eng. Prog. 98, $30-40$.

Moura, C. P., Vidal, C. B., Barros, A. L., Costa, L. S., Vasconcellos, L. C. G., Dias, F. S., et al. (2011). Adsorption of BTX (benzene, toluene, o-xylene, and pxylene) from aqueous solutions by modified periodic mesoporous organosilica. J. Colloid Interface Sci. 363, 626-634. doi: 10.1016/j.jcis.2011.07.054

Niu, H., Leung, D. Y. C., Wong, C., Zhang, T., Chan, M., and Leung, F. C. C. (2014). Nitric oxide removal by wastewater bacteria in a biotrickling filter. J. Environ. Sci. 26, 555-565. doi: 10.1016/S1001-0742(13)60456-8

Oppenländer, T. (2003). Photochemical Purification of Water and Air. Weinheim: Wiley-VCH.

Peral, J., and Ollis, D. F. (1997). $\mathrm{TiO}_{2}$ photocatalyst deactivation by gasphase oxidation of heteroatom organics. J. Mol. Catal. A 115, 347-354. doi: 10.1016/S1381-1169(96)00330-5

Qi, G., and Yang, R. T. (2004). Characterization and FTIR Studies of $\mathrm{MnOx}^{-\mathrm{CeO}_{2}}$ Catalyst for Low-Temperature Selective Catalytic Reduction of $\mathrm{NO}$ with $\mathrm{NH}_{3}$. J. Phys. Chem. 108, 15738-15747. doi: 10.1021/jp048431h

Quici, N., Vera, M. L., Choi, H., Puma, G. L., Dionysiou, D. D., Litter, M. I., et al. (2010). Effect of key parameters on the photocatalytic oxidation of toluene at low concentrations in air under $254+185 \mathrm{~nm}$ UV irradiation. Appl. Catal. $B$ 95, 312-319. doi: 10.1016/j.apcatb.2010.01.009

Radhakrishnan, R., and Oyama, S. T. (2001). Ozone decomposition over manganese oxide supported on $\mathrm{ZrO}_{2}$ and $\mathrm{TiO}_{2}$ : a kinetic study using in situ laser Raman spectroscopy. J. Catal. 199, 282-290. doi: 10.1006/jcat.2001.3167

Reed, C., Lee, Y.-K., and Oyama, S. T. (2006). Structure and oxidation state of silica-supported manganese oxide catalysts and reactivity for acetone oxidation with ozone. J. Phys. Chem. B 110, 4207-4216. doi: 10.1021/jp054288w

Rene, E. R., Murthy, D. V. S., and Swaminathan, T. (2009). Treatment of benzene vapors from contaminated air stream in a laboratory-scale compost biofilter. Macedonian J. Chem. Chem. Eng. 28, 119-123.

Rezaeia, E., Soltan, J., and Chen, N. (2013). Catalytic oxidation of toluene by ozone over alumina supported manganese oxides: effect of catalyst loading. Appl. Catal. B 136-137, 239-247. doi: 10.1016/j.apcatb.2013.01.061

Schwitzgebel, J., Ekerdt, J. G., Gerischer, H., and Heller, A. (1995). Role of the oxygen molecule and of the photogenerated electron in $\mathrm{TiO}_{2}$-photocatalyzed air oxidation reactions. J. Phys. Chem. 99, 5633-5638. doi: 10.1021/j1000 $15 \mathrm{a} 055$

Shayan, K., and Vahedpour, M. (2013). Computational study on the reaction mechanism of atmospheric oxidation of ethanol with ozone. Struct. Chem. 24, 611-621. doi: 10.1007/s11224-012-0111-2

Spigno, G., Pagella, C., Fumi, M. D., Molteni, R., and De Faveri, D. M. (2003). VOCs removal from waste gases:gas-phase bioreactor for the abatement of hexane by Aspergillus niger. Chem. Eng. Sci. 58, 739-746. doi: 10.1016/S00092509(02)00603-6
Standeker, S., Novak, Z., and Knez, Z. (2009). Removal of BTEX vapours from waste gas streams using silica aerogels of different hydrophobicity. J. Hazard. Mater. 165, 1114-1118. doi: 10.1016/j.jhazmat.2008.10.123

Thiruvenkatachari, R., Vigneswaran, S., and Moon, I. S. (2008). A review on $\mathrm{UV} / \mathrm{TiO}_{2}$ photocatalytic oxidation process (Journal Review). Korean J. Chem. Eng. 25, 64-72. doi: 10.1007/s11814-008-0011-8

Tompkins, D. T., Lawnicki, B. J., Zeltner, W. A., and Anderson, M. A. (2005). Evaluation of photocatalysis for gas-phase air cleaning-Part 1: Process, technical and sizing considerations. ASHRAE Trans. 111, 60-84.

Wang, C.-H. (2004). Al2O3-supported transition-metal oxide catalysts for catalytic incineration of toluene. Chemosphere 55, 11-17. doi: 10.1016/j.chemosphere.2003.10.036

Wang, C.-H., Lin, S.-S., Chen, C.-L., and Weng, H.-S. (2006). Performance of the supported copper oxide catalysts for the catalytic incineration of aromatic hydrocarbons. Chemosphere 64, 503-509. doi: 10.1016/j.chemosphere.2005.11.023

Wang, D., Oppenländer, T., El-Din, M. G., and Bolton, J. R. (2010). Comparison of the disinfection effects of Vacuum-UV (VUV) and UV light on Bacillus subtilis spores in aqueous suspensions at 172, 222 and $254 \mathrm{~nm}$. Photochem. Photobiol. 86, 176-181. doi: 10.1111/j.1751-1097.2009.00640.x

Wang, S., Ma, J., Liu, B., Jiang, Y., and Zhang, H. (2008). Degradation characteristics of secondary effluent of domestic wastewater by combined process of ozonation and biofiltration. J. Hazard. Mater. 150, 109-114. doi: 10.1016/j.jhazmat.2007.04.092

Wang, Y., Ge, C., Zhan, L., Li, C., Qiao, W., and Ling, L. (2012). MnOx$\mathrm{CeO} 2 /$ activated carbon honeycomb catalyst for selective catalytic reduction of NO with NH3at low temperatures. Ind. Eng. Chem. Res. 51, 11667-11673. doi: 10.1021/ie300555f

Wu, X. M., Fan, Z. T., Zhu, X., Jung, K. H., Ohman-Strickland, P., Weisel, C. P., et al. (2012). Exposures to volatile organic compounds (VOCs) and associated health risks of socio-economically disadvantaged population in a "hot spot" in Camden, New Jersey. Atmos. Environ. 57, 72-79. doi: 10.1016/j.atmosenv.2012.04.029

Xing, D., Cao, Y., Li, H., and Liu, F. (2000). Applications of membrane separation systems for VOC recovery. Membr. Sci. Technol. 4:011.

Yang, L., Liu, Z., Shi, J., Zhang, Y., Hu, H., and Shangguan, W. (2007). Degradation of indoor gaseous formaldehyde by hybrid VUV and $\mathrm{TiO}_{2} / \mathrm{UV}$ processes. Sep. Purif. Technol. 54, 204-211. doi: 10.1016/j.seppur.2006.09.003

Yang, Z., Yang, Y., Zhu, X., Chen, G., and Zhang, W. (2014). An outward coating route to $\mathrm{CuO} / \mathrm{MnO} 2 \mathrm{Nanorod}$ array films and their efficient catalytic oxidation of acid fuchsin dye. Ind. Eng. Chem. Res. 53, 9608-9615. doi: 10.1021/ ie $500358 \mathrm{p}$

Ye, J., Shang, J., Li, Q., Xu, W., Liu, J., Feng, X., et al. (2014). The use of vacuum ultraviolet irradiation to oxidize $\mathrm{SO}(2)$ and $\mathrm{NOx}$ for simultaneous desulfurization and denitrification. J. Hazard. Mater. 271, 89-97. doi: 10.1016/j.jhazmat.2014.02.011

Ye, J., Shang, J., Song, H., Li, Q., and Zhu, T. (2013). Generation of reactive oxygen species in simulated flue gas under vacuum ultraviolet radiation. Chem. Eng. J. 232, 26-33. doi: 10.1016/j.cej.2013.07.056

Yu, B. F., Hu, Z. B., Liu, M., Yang, H. L., Kong, Q. X., and Liu, Y. H. (2009). Review of research on air-conditioning systems and indoor air quality control for human health. Int. J. Refrig. 32, 3-20. doi: 10.1016/j.ijrefrig.2008.05.004

Yu, K. P., and Lee, G. W. M. (2007). Decomposition of gas-phase toluene by the combination of ozone and photocatalytic oxidation process $\left(\mathrm{TiO}_{2} / \mathrm{UV}, \mathrm{TiO}_{2} / \mathrm{UV} / \mathrm{O} 3\right.$, and UV/O3). Appl. Catal. B 75, 29-38. doi: 10.1016/j.apcatb.2007.03.006

Yuan, J., Huang, X., Chen, M., Shi, J., and Shangguan, W. (2013). Ozoneassisted photocatalytic degradation of gaseous acetaldehyde on $\mathrm{TiO}_{2} / \mathrm{M}-\mathrm{ZSM}-5$ $(\mathrm{M}=\mathrm{Zn}, \mathrm{Cu}, \mathrm{Mn})$. Catal. Today 201, 182-188. doi: 10.1016/j.cattod.2012.06.003

Zhang, P. Y., and Liu, J. (2004). Photocatalytic degradation of trace hexane in the gas phase with and without ozone addition: kinetic study. J. Photochem. Photobiol. A 167, 87-94. doi: 10.1016/j.jphotochem.2004.05.015

Zhao, J., and Yang, X. (2003). Photocatalytic oxidation for indoor air purification: a literature review. Build. Environ. 38, 645-654. doi: 10.1016/S03601323(02)00212-3

Zhao, X. S., and Lu, G. Q. (1998). Modification of MCM-41 by Surface Silylation with Trimethylchlorosilane and Adsorption Study. J. Phys. Chem. 102, 1556-1561. doi: 10.1021/jp972788m 
Zhu, W., Xiao, S., Zhang, D., Liu, P., Zhou, H., Dai, W., et al. (2015). Highly efficient and stable $\mathrm{Au} / \mathrm{CeO} 2-\mathrm{TiO}_{2}$ photocatalyst for nitric oxide abatement: potential application in flue gas treatment. Langmuir 31, 10822-10830. doi: 10.1021/acs.langmuir.5b02232

Zoschke, K., Bornick, H., and Worch, E. (2014). Vacuum-UV radiation at $185 \mathrm{~nm}$ in water treatment-a review. Water Res. 52, 131-145. doi: 10.1016/j.watres.2013.12.034

Zoschke, K., Dietrich, N., Börnick, H., and Worch, E. (2012). UV-based advanced oxidation processes for the treatment of odour compounds: efficiency and by-product formation. Water Res. 46, 5365-5373. doi: 10.1016/j.watres.2012.07.012
Conflict of Interest Statement: The authors declare that the research was conducted in the absence of any commercial or financial relationships that could be construed as a potential conflict of interest.

Copyright (c) 2016 Huang, Lu, Huang, Wang, Zhang and Leung. This is an openaccess article distributed under the terms of the Creative Commons Attribution License (CC BY). The use, distribution or reproduction in other forums is permitted, provided the original author(s) or licensor are credited and that the original publication in this journal is cited, in accordance with accepted academic practice. No use, distribution or reproduction is permitted which does not comply with these terms. 